South American Journal of Nursing

Special Edition 2016

\title{
Self-Image and Workplace Relations
}

\author{
Article Review by Marrie Davis \\ Nursing, Texila American University, Saint Vincent and the Grenadines \\ Email:- marriedavis63@hotmail.com
}

\begin{abstract}
The article outlines the effects transformational leaders impart among their followers. The outcomes inspired and aligned values obtained along with those of the organization. The purpose of the article, to give correct data on how transformational leadership affects self and personal outcomes; the need for personal advances, increased job satisfaction and both interpersonal and social relations. The article analyzed self-image and its impact on relations in the workplace. The last section reviewed recent advances related to the topic. The literature reviewed provided definitions of key terms. Many subsections, headings used to guide the reading process.
\end{abstract}

Keywords: self-image, self-concept, human relations, interpersonal skills, leadership

\section{Self-image and its impact on relations in the workplace}

The first part of the article critically analyzed self-image and its impact on relations in the workplace. The last aspect dealt with recent advances related to the topic. Many subsections with headings used to guide the reading process.

The literature review provided definition for key words. The article carefully evaluated and critiqued on its objectivity, authority, accuracy and theories relevant to the area of study. The major focus on transformational leadership discusses how leadership style affected followers on meeting their desired goals.

The analogy on transformational leadership and self-efficacy theory discussed. The use point method employed aided in outlining on how self-image impacted on relations in the work place.

\section{Review of literature}

Every organization continues to develop as well as an increase in the services of their customers. Relationships are now more important than the real product. Employees must not only able to get along with customers, but ably project a positive image of the organization they represent. One source of literature defined self-image environment as the belief that one can carry out scrupulous behavior to meet a desired goal related to one's health in the healthcare environment. Additionally, self-image is one's perception of their skills and uniqueness (Pastorino \& Doyle, 2013). Another source of literature clearly outlined Carl Rogers and Abraham Maslow two humanistic psychologist as the first two people develop the concepts of self. Moreover, "healthy people psychologically enthused move away from task created by others' prospect and look within themselves for justification. On the other hand, people who were afraid to accept their own experiences as applicable, change them to protect themselves or to win others approval”(Pastorino, 2013).

The self-categorization theory developed by John Turner stated that self-concept consisted of two levels, a personal identity and a social one. In other words, one's self-evaluation relies on self perceptions and on how others perceive them (Guimond, Serge; Chatard et al 2013).

Another article described human relations as an interdisciplinary field. This field of study entails human behavior in an organizational setting which involved communications, management, psychology and sociology. Both profit and nonprofit organizations defined human relations as fitting people into work situations. The literature further attested this strategy helps to 
motivate employees to work together in harmony. The course of action allowed for higher levels of organizational achievements and productivity, and had brought to employees economics, psychology and social satisfaction. However, human relations cover all aspects of interactions among people and their conflicts, as a cooperative efforts and group relationships (Encyclopedia of Business, 2007).

One of the most significant developments in recent years had been the increased importance of interpersonal skills in every job setting. Many employers believe interpersonal skills represent an important group of transferable skills that any worker ought to bring to the job. Technical abilities only are not enough to make career success the literature asserted. Studies indicated that many people who had met difficulties in obtaining or holding a job have the needed technical competencies, but lack of interpersonal competencies (Encyclopedia of Business, 2007).

Nemov (1 998) described leadership as a shining and fascinating phenomena that arose in the course of human relations. According to the author interpersonal relation seen as part of human nature and a need in communicating. One author affirmed, the major principle of transformational leadership theory allows leaders to encourage their followers to do more than what planned. The form of leadership allowed to idealized influence, inspirational motivation, intellectual stimulation and personal consideration (Krishnan, 2005).

\section{Article summary}

Psychological perspective viewed the self as 'holism', an individual's behavior connected to people inner-feelings and self-image. Moreover, each person is unique, has the free will to change at any given time throughout their life span. Everyone is responsible for his or her own happiness and well-being, more so, has an innate capacity for actualization. Each person experience is personalized.

Human relation an interdisciplinary field and the images portrayed in the working environment significantly has an impact on both profit and nonprofit organizations. The hypothesis formed the basis for improving self-image and its relations in the healthcare environment. The literature provided on transformational leadership theory imparted positive linked to different outcomes in organizations. Convincingly, transformational leaders influenced employees' behavior, improve relations and contributed to the changing trends in the workplace.

Transformational leadership has associated with personal outcomes. Therefore, the article provides detailed information on self-image, relationships and how these factors affected the workplace. The facts made available readily used to improve self-image and workplace relationships. "Leaders are the ones who motivate followers to do more than what initially expected to do. Also, leaders urge followers to go beyond self-interest for the good of self, team or organization” (Bass, 1 995).

\section{Article structure}

The article specifically outlined the point of view; the effects transformational leaders imparts on their followers. The effects inspired morals and helped to align the values obtained with those of the organization. The goals of the article- to give defined evidence how transformational leadership affects the self-image and personal outcomes; and allowed for personal progress, improved job satisfaction and improved both interpersonal and social relations.

Each topic sentence identified by headings, short paragraphs and evidently stated. However, no specific studies conducted. Previous studies had documented importance connections between transformational leadership and organizational operation. The literature provided contained conventional information about the study and defined key terms. Background information underpins how employees' behavior influenced by transformational leaders and the positive impression on the working environment. 
Method and data collection were not present, tables used for evaluation of technique, test selfcategorization and personal outcomes. The synopsis showed positive effects and personal outcomes of earlier studies. Proposal made for added research. Hence, empirical research related to the results will give better approach into theory development related to organizational behavior and the direct connection between transformational leadership. Also, further study could investigate possible mediators of transformational leadership and personal behavior. References cited in-text and set out in the literature.

The structure was logically developed with very short paragraphs which made reading easier and access main points. The article, a PDF document and no link included. Links to author, subjects and journal allowed for proper evaluation of article.

\section{Article critique}

\section{Authority}

Review on author: Author Roger Given was a senior publisher at the Green River Ramblin's Publication, Morgantown, Kentucky University, United States of America. Roger Given retired; a newspaper publisher who used images from the Kentucky Library and private people to create photographic essay. This author credibility established in many ways, as a Regent University Doctoral Student. His interest was in understanding transformational leadership, socialization, and psychological empowerment with emphasis on the relationship between leader and followers in the $21^{\text {st }}$ century especially in the African-American Church.

Roger Givens serving on the Morgantown, Butler Country Chamber of Commerce, Board of Directors, Green River Museum, Boards of Director, and Kentucky Historical Highway Marker as Chairperson. Presently, he is the Vice President of the Charles Duncan Chapter, Sons of the American Revolution and an amateur historian.

The former co-publisher of the Butler Banner newspaper and co-author of Images of America. Roger Givens also, wrote several weekly articles on historical events, people and places. He published his current book "African American Life in Butler Country, Kentucky-Black Culture, Contributions and Community” and the $200^{\text {th }}$ Anniversary saga and historical booklet.

\section{Accuracy}

The source of information provided was relatively current. References recent and list with the necessary sources cited in- text to support the literature review. An example of the accuracy of sources used; "self-efficacy belief has been a focus of organizational research for nearly three decades” (Bandura, 1986; Luthans, 2002).

The stringent editorial and refereeing processes contributed to the accuracy of the article “Emerging Leadership Journeys”. The viewpoint investigated the effects of transformational leadership style on organizational and personal outcomes and linked to other expert sources:

- The exegesis advances a spirit-empowered leadership model,

- The effect of follower self-concept and self-determination of organizational behavior

- The concept paper reflects on organizational metaphors

- The relationships between organizational mission, power, structure and resources

Therefore, these linkages of editorials contributed to the accuracy and skills of the journal.

\section{Currency}

The journal published in April 2008 and accepted for publication the same year. The research described was current. The article cited up-to-date references in the body of the text ranged from 1954 to 2007. Due to the fact, mentioned made on Maslow Hierarchy Theory (1954) and the effects of the theory on self-actualization. 
There were many volumes issued from 2008 to 2013. For these reasons, the article is considered current.

\section{Relevance}

The journal received high credibility at a doctoral level. The article is relevant to any group due to its contextual content. The commentary has been proven pertinent from a group perspective and nursing academia. The editorial is accessible and comprehensible. The innovative aspects focused on self-efficacy principles an individual's belief in his or her capabilities to successfully carry out specific or set task.

In addition, self-image described as the confidence in which followers had successfully achieved and the values attached to particular personal outcomes. S elf-efficacy had since influenced patterns of thoughts, emotions and actions. Leaders and followers had spent much effort searching goals and exercising control over events that had affected their lives. The article is pertinent to first year nursing students. According to one author "individual success requires training, skills and personal belief. Hence, transformational leaders are able to augment selfefficacy of followers by self-assurance. Moreover, help people to work through identified problems and significant challenges” (Luthans, 2002).

Being committed is much applicable to nursing students. The concept of commitment is an internal agreement and the enthusiasm when carrying out a request or task (Yukl, 2002). In addition, individual's work experiences and personal factors serve as antecedents to organizational commitment and can only be achieved through leadership.

\section{Objectivity}

The evidence found involved the following:-

- The transformational leaders ably motivate, be committed and empowered followers. The performance motivated beyond expectations, through the ability to influence attitudes

- Followers inspired and motivated by their leaders as role model recognizing the uniqueness and creativity. Transformational leader built an interactive relationship based on trust that positively changed both leaders and followers.

- The relations developed allowed for leaders and followers to focus, created unity and wholeness.

- The high performance of leadership style showed a high commitment to the profession and the organization, challenged obstacles by using group learning and created a synergistic environment and enhanced change. The change occurred due to futuristic leadership focus and values. Additionally, the leader's value of organizational culture perpetuated the importance and staff behavior.

Evidence well acknowledged and supported by current references. Previous research conducted had clearly established the effects of transformational leadership and its impacts in the workplace. The leadership style encouraged followers to go beyond self-interest and the direct effects of organizational citizenship, behavior and performance. In general, it idealized influence, inspired enthusiasm and allowed followers to think critically.

The distinctiveness of transformational leader test in the workplace and the necessary skills displayed practically. Referring to the literature review pertinent terminology was clearly defined.

\section{Stability}

Emerging Leadership Journal (ELI) is an academic journal. It provided a forum for emerging scholars in the field of leadership studies. Philosophy of Doctorate students enrolled in the program, Organizational Leadership in Regent University School of Business and Leadership are contributors. 
Biannually the best research papers submitted during the first four terms of their doctoral journey published. These papers reflected the students' academic understanding the phenomenon of leadership.

Journal articles reprinted in accordance with the policy as described in the United States Copyright Law. Anyone wishing to reprint the university articles for commercial use or monetary gain must ask permission and pay the associated fee.

\section{Analysis of tables}

Two tables used to critically analyze personal and organizational outcomes Organizational outcomes- the following analysis characterized:-

- Organizational citizenship behavior and performance based on related studies showed positive benefits and improved employee's performance (Nguni, 2006).

- Cultural perspective- studies proven- the influence of leaders on employees, its impacts of commitment and revision of shared assumptions and values (Jones, 2007).

- Vision- followers became critical thinkers and new opportunities revealed. Followers aspired to reach their potential (Zaccaro, 2001).

Critical areas identified personal outcomes, commitment, trust, self-efficacy beliefs, enthusiasm and empowerment.

- Trust, an essential element in relationship (Podsakoff, 2000).

- Empowerment - the participating environment and followers as critical thinkers (Masi, 2000).

- Commitment -being enthused, the evident skills and experiences. Organizational and personal factors serve as the antecedents (Nguni, 2006).

- Self-efficacy beliefs- increased as leader showed confidence in their followers. Also, influenced patterns of thoughts, emotion and actions (Bandura, 1977).

- Motivation- the extra effort an indicator and increased when leader showed confidence in followers (Bass, 1988).

\section{Recent advances related research to the topic}

Today, nursing leaders need to change their organization's values, beliefs and behavior. Through reforming their clinical knowledge and ability on professional practices, vision, influence and personality. Efforts achieved through the capable ventures of transformational leaders. Followers who inspire change should work toward their expectations, perceptions and motivations on attaining common goals. Additionally, transformational leaders garner trust, respect and admiration from their followers.

However, recent findings identified key components of transformational leadership:-Strategic Planning

- Align nursing's vision, mission, values, quality strategic planning with organizational plan.

- Provision of the necessary mechanisms for all staff to advocate for resources, these factors will help to improve the organization's effectiveness and efficiency.

Advocacy and influence

- Guide the changing process by supporting, encouraging, implementing and reward innovations.

- Performance management - mentoring, coaching, evaluation of staff performance and succession planning

Visibility, accessibility and communication

- Communicate or ask for comments to enhance working environment and most importantly patient care

- Establish lines of communication across the hierarchy "everyone must sing from the same song sheet” in order to build a good and support relationships (Alnabulsi, 2014 ). 
South American Journal of Nursing

Special Edition 2016

\section{Self-efficacy theory}

Self-efficacy theory (SET) attested that one has the power to produce and complete any given task or activity related to the competency. However, these qualities can only be realized based on several factors-

Individual's perception and ability to meet the goal

- The ability to do

- The mastery of the situation, procedure to produce a positive outcome

- The importance of self-efficacy

Factors that influence self-efficacy according to Bandura's Social Cognitive Model (2012).

- Behaviors

- Environment

- Personal or cognitive factors.

Self-efficacy plays a major function on how goals, task and challenges set about. The theorist further explained beliefs began to form in early childhood. "Children experience great deal and variety of experiences, tasks and situations. The growth of self-efficacy continues to develop throughout the life as people acquire new skills, experiences and understanding”. The theorist further stated, learning occurs based on three aspects self-reflective, self-regulating and selforganizing and the process take place through observational learning (Feist, 2009).

Humanistic Psychologist Maslow believes love and belonging are the primal needs to fulfilled. Maintaining relationship with others, making friends and family are vital and necessary for levels of people success (Feist, 2009). Perspectives of humanistic psychologists viewed interpersonal relationships as part of human lives. Also, allowed for growth and development and healthy psychological well-being, vital components in personal development (Hoffman, 2004).

Social constructivism claimed information, behavior and personality originate from social engagement. Individual build new ideas and concepts based on current knowledge and experience. Social psychologists believe learning derived from observation and stunted without social experience growth and development (Feist, 2009).

\section{Conclusion}

Roger Given a senior publisher at the Green River Ramblin's Publication, in the United States of America. The article Emerging leadership Journeys received high accreditation. The various literature sources critically defined key terms and importance of theory in the review. The article very relevant to leadership in the $21^{\text {st }}$ century and first year nursing students in the field of leadership, actualization and enthusiasm.

The transformational leadership style is valuable in the field of nursing administration to guide the profession forward and to meet efficient organizational outcomes. Background information underpins how employees' behavior influenced by transformational leaders and the positive impression on the working environment.

PDF article with information clearly outlined, headings and tables allowed for easy access the information. The summary showed the positive affects organizational and personal outcomes based on connections of earlier research.

Recommendation made for further research. Hence, empirical research on outcomes provided a more insight into theories developed no organizational behavior and the direct connection between transformational leadership.

Also, further research could investigate any possible mediators of transformational leadership and personal behavior. 


\section{References}

[1]. Alnabulsi, H. \&. (2014). Social identification moderates the effect of crowd density on safety at the Hajj. Proceedings of the National Academy of Sciences., 111(25), 9096-9096.

[2]. Bandura, A. (1986). Social foundations of thought and action: A social cognitive theory. NJ.: Prentice-Hall.

[3]. Bass, B. (1985). Leadership and performance beyond expectations. New York: The Free Press.

[4]. Encyclopedia of Business and Finance, 2ed. (2007). Highland: Patrick.

[5]. Feist, J. \&. (2009). Theories of Personality (7th Eds). NY.: McGraw Hill.

[6]. Givens, R. (2014). African American Life in Butler Country, Kentucky, Black Culture Contribution. Kentucky.: Arcadia Publishing.

[7]. Guimond, S., Chatard, A., Martinot, D., Crisp, R. J., \& Redersdorff, S. (2006). "Social comparison, selfstereotyping, and gender differences in self-constructs". Journal of Personality and Social Psychology., 90 (2).

[8]. Hoffman, L. (2011, May 08th). Existential Therapy Home page. Retrieved from existential-therapy.com: http://www.extistential-therapy.com/Index.htm

[9]. Jones, T. F. (2007). Ethical theory and stakeholder-related decisions: The role of stakeholder culture. Academy of Management Review., 32 (1), 137-155.

[10]. Krishnan, V. (2005). Transformational leadership and value system congruence. International Journal of value-based Management., 19-33.

[11]. Longnecker, P. (2006). Evaluating transformational leadership skills of hospice executives. American Journal of Hospice and Palliative Medicine., 23 (3), 205-211.

[12]. Luthans, F. (2002). Positive organizational behavior: Developing and managing psychological strengths. Academy of Management Executive., 16 (1), 57-72.

[13]. Luthans, F. (2002). The need for and meaning of positive organizational behavior. Journal of Organizational Behavior., 23, 695-706.

[14]. Luthans, F. (2002). The need for and meaning of positive organizational behavior. Journal of Organizational Behavior., 16 (1), 57-72.

[15]. MacKenzie, S. P. (2001). Transformational and transactional leadership and salesperson performance. Journal of the Academy of Marketing Science, 29, 115-134.

[16]. Masi, R. \&. (2000). Effects of transformational leadership on subordinate motivation, empowering norms, and organizational productivity. The International Journal of Organizational Analysis., 8(1), 16-47.

[17]. Mc Guire, E. \&. (2006). Nurse managers as transformational and transactional leaders. Nurses Economics, 24(4).179-186.

[18]. McLeod, S. (2015, January 21). Simply psychology. Retrieved from http://www.simplypsychology.org/socialidentity-theory.html.: HTML

[19]. Nemov, R. (1998). Psychology. Practical Psychology, pp 278.

[20]. Nguni, S. S. (2006). Transformational and transactional leadership effects on teachers' job satisfaction, organizational commitment, and organizational citizenship behavior in primary schools: Tanzanian case. School Effectiveness and School Improvement., 17 (2), 145-177.

[21]. Pastorino, E. \&. -P. (2013). What is Psychology?: Essentials. Belmont, CA: Wadswort.

[22]. Yukl, g. (N.d.).

[23]. Yukl, G. (2002). Leadership in organizations (5th Ed.). NJ.: Prentice-Hall.

[24]. Zaccaro, S. \&. (2001). Leadership, vision and organizational effectiveness. In J. K. In S.J. Zaccaro \& R, The nature of organizational leadership. (Pp. 181-218). San Francisco: Jossey-Brass. 